University of Wollongong

Research Online

Australian Institute for Innovative Materials -

Papers

Australian Institute for Innovative Materials

$1-1-2016$

\title{
A ferroelectric photocatalyst Ag10Si4013 with visible-light photooxidation properties
}

Amar Al-Keisy

University of Wollongong, ahjak378@uowmail.edu.au

Long Ren

University of Wollongong, Ir289@uowmail.edu.au

Dandan Cui

Beihang University

Zhongfei Xu

Beihang University

Xun Xu

University of Wollongong, xun@uow.edu.au

See next page for additional authors

Follow this and additional works at: https://ro.uow.edu.au/aiimpapers

Part of the Engineering Commons, and the Physical Sciences and Mathematics Commons

Research Online is the open access institutional repository for the University of Wollongong. For further information contact the UOW Library: research-pubs@uow.edu.au 


\title{
A ferroelectric photocatalyst Ag10Si4013 with visible-light photooxidation properties
}

\author{
Abstract \\ Ferroelectric p-block semiconductors are regarded as a new family of visible-light photocatalysts because \\ of their dispersive and anisotropic band structures, as well as their intrinsic internal electric field. Silver \\ silicates belong to this family and have band structures and an internal electric field that can be \\ engineered by modulating the stoichiometry of $\mathrm{Ag}$ and SiO4. Here, we have developed a new ferroelectric \\ p-block photocatalyst, Ag10Si4013, by materials design and band engineering, which exhibits excellent \\ photocatalytic activity towards the degradation of organic compounds, which is driven by visible light. \\ Owing to the unique $\mathrm{d} 10$ and $\mathrm{sp} / \mathrm{p}$ configurations in its electronic structure, Ag10Si4013 possesses an \\ indirect band gap of $1.72 \mathrm{eV}$ with a highly dispersive conductive band and a flat valence band. This \\ electronic structure promotes the generation, separation, and mobility of photo-induced charge carriers \\ under visible-light illumination, which has been verified experimentally and theoretically. The compatible \\ energy level of the conduction band determines its strong photo-oxidative capability. Moreover, the charge \\ transfer process takes advantage of the existence of an internal electric field in Ag10Si4013, which is \\ attributed to the distorted $\mathrm{SiO} 4$ chain structure.

\section{Disciplines} \\ Engineering | Physical Sciences and Mathematics

\section{Publication Details} \\ Al-Keisy, A., Ren, L., Cui, D., Xu, Z., Xu, X., Su, X., Hao, W., Dou, S. X. \& Du, Y. (2016). A ferroelectric \\ photocatalyst Ag10Si4013 with visible-light photooxidation properties. Journal of Materials Chemistry A, \\ 4 (28), 10992-10999.

\section{Authors} \\ Amar Al-Keisy, Long Ren, Dandan Cui, Zhongfei Xu, Xun Xu, Xiangdong Su, Weichang Hao, S X. Dou, and Yi \\ $\mathrm{Du}$
}




\title{
A Ferroelectric Photocatalyst $\mathrm{Ag}_{10} \mathrm{Si}_{4} \mathrm{O}_{13}$ with Visible-light Photooxidation Propertiest
}

\author{
Amar Al-keisy, ${ }^{\perp}$ a Long Ren, ${ }^{\perp a}$ Dandan Cui, ${ }^{\mathrm{b}}$ Zhongfei $\mathrm{Xu},{ }^{\mathrm{b}}$ Xun $\mathrm{Xu},{ }^{\text {a d }}$ Xiangdong Su, ${ }^{\mathrm{c}}$ Weichang \\ $\mathrm{HaO},{ }^{b{ }^{*}}$ Shi Xue Dou, ${ }^{a} \mathrm{Yi} \mathrm{Du}^{\text {ad }}$ \\ The ferroelectric $p$-block semiconductors are regarded as a new family of visible-light photocatalysts because of their \\ dispersive and anisotropic band structures, as well as their intrinsic internal electric field. Silver silicates belong to this \\ family and have band structures and internal electric field that can be engineered by modulating the stoichiometry of $\mathrm{Ag}$ \\ and $\mathrm{SiO}_{4}$. Here, we have developed a new ferroelectric $p$-block photocatalyst, $\mathrm{Ag}_{10} \mathrm{Si}_{4} \mathrm{O}_{13}$, by material design and band \\ engineering, which exhibits excellent photocatalytic activity towards the degradation of organic compounds, which is \\ driven by visible light. Owing to the unique $d^{10}$ and $s p / p$ configurations in its electronic structure, $\mathrm{Ag}_{10} \mathrm{Si}_{4} \mathrm{O}_{13} \mathrm{possesses}$ an \\ indirect band gap of $1.72 \mathrm{eV}$ with a highly dispersive conductive band and a flat valence band. This electronic structure \\ promotes the generation, separation, and mobility of photo-induced charge carriers under visible-light illumination, which \\ has been verified experimentally and theoretically. The compatible energy level of the conduction band determines its \\ strong photo-oxidative capability. Moreover, the charge transfer process takes advantage of the existence of an internal \\ electric field in $\mathrm{Ag}_{10} \mathrm{Si}_{4} \mathrm{O}_{13}$, which is attributed to the distorted $\mathrm{SiO}_{4}$ chain structure.
}

\section{INTRODUCTION}

Photocatalysis is one of the most promising ways to solve the energy crisis and environmental pollution issues by using solar energy. ${ }^{1-11}$ A number of photocatalysts have been proposed and prepared using materials design and band engineering techniques. Some have achieved excellent photocatalytic performance in either water splitting or the elimination of organic pollution. Nevertheless, most of the high-performance photocatalysts proposed so far are transition metal oxide (TMO) based materials. Generally, TMOs have wide band gaps (> $3.0 \mathrm{eV}$ ) due to partially filled $\mathrm{d}$ orbitals, ${ }^{12-15}$ which limits the absorption of visible light. In addition, their valence bands (VBs) and conduction bands (CBs) are less dispersive due to the isotropic $d$ orbitals of transition metals (TM). The photo-induced charge carriers are hence given a large effective mass, which hinders charge separation and mobility, and results in low quantum conversion efficiency in photocatalysis, especially in the visible light spectrum. Consequently, their visible-light photocatalytic performances are not as high as desired. Therefore, the exploration and

${ }^{a}$ Institute for Superconducting and Electronic Materials (ISEM), Australian Institute for Innovative Materials (AIIM), University of Wollongong, Wollongong, NSW 2525, Australia*E-mail for Y. D. : yi du@uow.edu.au

${ }^{b}$ Department of Physics and Key Laboratory of Micro-nano Measurement Manipulation and Physics, Ministry of Education (MOE), Beihang University, Beijing 100191, China*E-mail for W. H. : whao@buaa.edu.cn

${ }^{c}$ School of Materials and Metallurgy, Guizhou Institute of Technology, Guizhou 550007, China

${ }^{d}$ UOW-BUAA Joint Research Centre, University of Wollongong, Wollongong, NSW 2525, Australia

$\dagger$ Electronic Supplementary Information (ESI) available: See DOI: 10.1039/x0xx00000x

Authors contributed equally. development of new visible-light responsive photocatalysts with high quantum conversion efficiency through materials design and band engineering have emerged as an urgent and challenging task in the field of photocatalysis.

Recently, AgO-based compounds have been reported with excellent visible-light-driven photocatalytic activities, ${ }^{16-24}$ because of their unique electronic configurations. Since the $d$ orbitals of $\mathrm{Ag}$ are fully filled, the $p$ orbitals in these compounds play an important role in the energy levels and dispersion of the VB and CB. Generally, $p$ orbitals lift the top of the VB and/or lower the bottom of the $C B$ in AgO-based photocatalysts, and promote generation of photo-induced electrons and holes under visible light. Moreover, highly dispersive VBs or CBs can be formed due to anisotropic $p$ or hybridized $s p$ states. As a result, the effective mass of photoinduced charge carriers is much smaller in AgO-based compounds, which facilitates charge transfer in the photocatalytic process under visible-light irradiation. ${ }^{25,26}$ Nevertheless, the narrow band gap and dispersive electronic structure also facilitate the recombination of electrons and holes in the photocatalytic process and, in turn, would limit the photocatalytic activities of these compounds. Therefore, AgO-based compounds with efficient charge separation in photocatalysis are still desired, although their visible-light photocatalytic performance is much higher than those of the TMOs. Among these AgO-based compounds, an Agincorporated $p$-block family, silver silicate $\left(\mathrm{Ag}_{x} \mathrm{Si}_{y} \mathrm{O}_{z}\right){ }^{19,20,24}$ has captured our attention recently. Besides the unique $d^{10}$ state of $\mathrm{Ag}$, both $\mathrm{Si}$ and $\mathrm{O}$ in $\mathrm{Ag}_{x} \mathrm{Si}_{y} \mathrm{O}_{z}$ have typical $s p / p$ electronic configurations, which make the band gap, and the VB and CB in $\mathrm{Ag}_{x} \mathrm{Si}_{y} \mathrm{O}_{z}$ very likely to conform to the optimum electronic structure for visible-light-driven photocatalysts. In particular, 
an internal electric field is expected in $\mathrm{Ag}_{x} \mathrm{Si}_{y} \mathrm{O}_{z}$ compounds, owing to the spontaneous electronic polarization induced by the distorted tetrahedral unit $\left(\mathrm{SiO}_{4}\right)$ arrangement. ${ }^{27-29}$ This internal electric field can effectively promote spatial charge separation, which addresses the electron-hole recombination issues that are found in the other AgO-based compounds. Moreover, the strength of the internal electric field can be feasibly modulated by the number of distorted arrangements of $\mathrm{SiO}_{4}$ tetrahedral, and enhances the photocatalytic activity of silver silicate. As a consequence, $\mathrm{Ag}_{x} \mathrm{Si}_{y} \mathrm{O}_{z}$ is regarded as a promising compound family for exploring new visible-lightdriven photocatalysts because of these unique crystal and electronic structures. Nevertheless, there have been very few investigations aimed at the design and development of $\mathrm{Ag}_{x} \mathrm{Si}_{y} \mathrm{O}_{z}$ photocatalysts so far.

In this work, we report a new visible-light-driven silver silicate photocatalyst, $\mathrm{Ag}_{10} \mathrm{Si}_{4} \mathrm{O}_{13}$, which demonstrates high photocatalytic activity towards the elimination of organics. It was found that the excellent photocatalytic performance of $\mathrm{Ag}_{10} \mathrm{Si}_{4} \mathrm{O}_{13}$ originates from its anisotropic and highly dispersive band structure due to its $p$-block electronic configuration. Moreover, $\mathrm{Ag}_{10} \mathrm{Si}_{4} \mathrm{O}_{13}$ is expected to have a large ferroelectric polarization due to long distorted $\mathrm{SiO}_{4}$ chains in comparison to the other $\mathrm{Ag}_{x} \mathrm{Si}_{y} \mathrm{O}_{z}$ ferroelectric materials. It induces an intrinsic internal electric field in $\mathrm{Ag}_{10} \mathrm{Si}_{4} \mathrm{O}_{13}$, which further enhances the photocatalytic activity by effective separation of photoinduced charges. Our experimental and theoretical results suggest that silver silicates are promising candidate materials to explore visible-light-active photocatalysts through structural and electronic engineering.

\section{EXPERIMENTAL SECTION}

Sample preparation. In a typical experimental process, $\mathrm{AgNO}_{3}$ and $\mathrm{Na}_{2} \mathrm{SiO}_{3}$ (99.9\%, Sigma-Aldrich Company) were mixed in a mortar in a molar ratio of 2:1 and then pressed into a disk $1 \mathrm{~cm}$ in diameter and $3 \mathrm{~mm}$ in thickness. The disk was heated in air at 400 으 for $2 \mathrm{~h}$. After that, the product was washed three times with distilled water and ethanol to remove residual $\mathrm{NaNO}_{3}$ and $\mathrm{AgNO}_{3}$. The sample was dried at 60 o $\mathrm{C}$ for $12 \mathrm{~h}$. For comparison, the photocatalytic activity of $\mathrm{N}$ doped $\mathrm{TiO}_{2}$ was synthesized according to the original report. ${ }^{2}$

\section{Sample characterizations.}

The purity and crystallinity of the sample were investigated by $\mathrm{X}$-ray diffraction (XRD, GBC, MMA) using $\mathrm{Cu}$ K $\alpha$ radiation with $\lambda$ $=1.5418 \AA$ A. The sample morphology and elemental analysis were investigated by field emission scanning electron microscopy (FESEM, JEOL-7500). The composition of the samples was examined by energy dispersive spectroscopy (EDS) attached to the FESEM. Transmission electron microscope (TEM) images and SAED patterns were obtained using a JEOL ARM-200F. X-ray photoelectron spectroscopy (XPS, PHI660) was performed using a monochromatic Mg K $\alpha$ Xray source. An ultraviolet-visible spectrophotometer (UV-Vis, Shimadzu-3600) was used to measure diffuse reflectance spectra (DRS) by adding an integrating sphere attachment to the instrument, with $\mathrm{BaSO}_{4}$ providing a background between $200 \mathrm{~nm}$ and $800 \mathrm{~nm}$. The polarization as a function of electric field was obtained using an Easy Check 300 (aixACCT Systems $\mathrm{GmbH}$ ) equipped with a Trek $610 \mathrm{E}$ high voltage source. In the photocurrent-time response system, a $300 \mathrm{~W}$ Xe lamp with a monochromator and a cut-off filter $(\lambda>400 \mathrm{~nm})$ was used as the light source. The photocurrent as a function of irradiation time under visible light was collected by a KEITHLEY 2400 source meter. The surface photovoltage (SPV) spectroscopy apparatus is composed of a source of monochromatic light, a lock-in amplifier (SR830-DSP) with a light chopper (SR540), and a photovoltaic cell. A $500 \mathrm{~W}$ Xe lamp (CHFXQ500W, Global Xenon Lamp Power) and a grating monochromator (Omni-5007, no. 09010, Zolix) provide monochromatic light. The construction of the photocurrenttime-response cell and the photovoltaic cell was in the form of a sandwich-like structure of indium tin oxide (ITO)-sample-ITO. The Mott-Schottky curves were collected with a PARSTAT-2273 Advanced Electrochemical System (Princeton Applied Research). The $\mathrm{Ag}_{10} \mathrm{Si}_{4} \mathrm{O}_{13}$ film, Pt foil, SCE, and saturated $\mathrm{KCl}$ solution were used as working, counter, and reference electrodes, and as the electrolyte, respectively. The working electrode was prepared via the dip-coating method. The MottSchottky measurements were monitored at a fixed frequency of $100 \mathrm{~Hz}$ with $10 \mathrm{mV}$ amplitude at various potentials.

Photocatalytic activity measurements. Rhodamine B (RhB), methyl orange $(\mathrm{MO})$, methylene blue $(\mathrm{MB})$, and phenol were used as target organics in photocatalytic degradation tests. All the dyes and the phenol were purchased from Sigma-Aldrich. The photocatalytic activity was carried out at room temperature using $\mathrm{Ag}_{10} \mathrm{Si}_{4} \mathrm{O}_{13}$ as photocatalyst. The light source used in the photocatalytic measurements was a $300 \mathrm{~W}$ $W$-Xe lamp with a UV cut-off filter $(\lambda>420 \mathrm{~nm})$. In a typical process, $100 \mathrm{ml}$ of $\mathrm{RhB}, \mathrm{MO}$, or $\mathrm{MB}$ solution $(10 \mathrm{mg} / \mathrm{L}$ for all dyes) and $0.1 \mathrm{~g} \mathrm{Ag}_{10} \mathrm{Si}_{4} \mathrm{O}_{13}$ were added together in a $250 \mathrm{ml}$ beaker. The suspensions were magnetically stirred in the dark for $30 \mathrm{~min}$ to reach adsorption-desorption equilibrium, and then the mixture was exposed to the light source. The photodegradation of the dye solutions was analysed by UV-Vis spectrophotometer. To stand in for real organic pollutants, phenol was used under the same conditions, but the concentration and volume were $20 \mathrm{mg} / \mathrm{L}$ and $50 \mathrm{ml}$ respectively, a sample taken every $20 \mathrm{~min}$. For comparison, the photocatalytic activity of $\mathrm{N}$ doped $\mathrm{TiO}_{2}$ was measured under the same conditions.

Theoretical calculations. The calculations were carried out using the Vienna Ab-initio Simulation Package (VASP) based on density functional theory with the projector augmented wave (PAW) pseudopotential method. We applied hybrid functional calculations to simulate ferroelectricity in this work. The shortrange exchange potential was calculated by mixing a fraction of nonlocal Hartree-Fock exchange with the generalized gradient approximation (GGA) functional of Perdew, Burke, and Ernzerhof (PBE). A conjugate-gradient algorithm was used to relax the ions into their ground states, and the energies and 
the forces on each ion were converged within $1 \times 10^{-5} \mathrm{eV} /$ atom and $0.01 \mathrm{eV} / \AA$, respectively. The Koln-Sham orbitals were expanded by a plane wave basis set, and an energy cut-off of $550 \mathrm{eV}$ was used throughout. The Brillouin-zone integration was performed by using the Gamma-centered Monkhorst-Pack scheme with $6 \times 4 \times 3$ k-points.

\section{RESULTS AND DISCUSSION}

The X-ray diffraction (XRD) pattern of the as-prepared sample is shown in Fig. 1a. All the diffraction peaks can be indexed to $\mathrm{Ag}_{10} \mathrm{Si}_{4} \mathrm{O}_{13}$ with a triclinic structure (space group $P$ $1)$, according to the Joint Committee on Powder Diffraction Standards (JCPDS) Card No. 01-071-1365. The sample consists of phase-pure reddish powders without any observable impurities. In the triclinic structure of $\mathrm{Ag}_{10} \mathrm{Si}_{4} \mathrm{O}_{13}$, as illustrated in the inset of Fig. $1 \mathrm{a}$, four tetrahedral $\mathrm{SiO}_{4}$ units are connected through a corner-shared oxygen atom, forming a distorted $\mathrm{Si}_{4} \mathrm{O}_{13}$ chain which is coordinated with the $\mathrm{Ag}$ ions. The field emission scanning electron microscope (FESEM) images reveal that the as-prepared $\mathrm{Ag}_{10} \mathrm{Si}_{4} \mathrm{O}_{13}$ sample consists of micronsized irregular particles (Fig. 1b). As shown in Fig. S1t, the selected area electron diffraction (SAED) pattern verifies excellent crystallinity of the $\mathrm{Ag}_{10} \mathrm{Si}_{4} \mathrm{O}_{13}$ sample. HRTEM results clearly show the lattice fringes of as-prepared $\mathrm{Ag}_{10} \mathrm{Si}_{4} \mathrm{O}_{13}$ particles with d-spacing of 0.197 and $0.279 \mathrm{~nm}$, which can be assigned to $(-104)$ and $(-411)$ directions of triclinic structure, respectively. The elemental composition and chemical states of $\mathrm{Ag}_{10} \mathrm{Si}_{4} \mathrm{O}_{13}$ were further analysed by $\mathrm{X}$-ray photoelectron spectroscopy (XPS), as shown in Fig. 1c. The survey spectrum demonstrates that the main peaks correspond to $\mathrm{Ag} 3 d_{5 / 2}$ and Ag $3 d_{3 / 2}, \mathrm{O} 1 s$, and $\mathrm{Si} 2 p$ orbitals for the $\mathrm{Ag}_{10} \mathrm{Si}_{4} \mathrm{O}_{13}$ sample. Detailed spectra providing the fine information for $\mathrm{Ag}, \mathrm{Si}$, and $\mathrm{O}$ are presented in (Fig. S1c, S1d and S1et) in which the peaks of $\mathrm{Ag} 3 \mathrm{~d}_{5 / 2}$ and $\mathrm{Ag} 3 \mathrm{~d}_{3 / 2}$ are located at $367 \mathrm{eV}$ and $373 \mathrm{eV}$, whereas the peaks of Si $2 p$ and $O 1 s$ are located at $100.8 \mathrm{eV}$ and $530.6 \mathrm{eV}$, respectively. The valences of $\mathrm{Ag}$ and Si are thus identified as +1 and +4 , respectively. The energy dispersive spectroscopy (EDS) spectrum shows (Fig. S1ft) that the atomic percentages of $\mathrm{Ag}, \mathrm{Si}$, and $\mathrm{O}$ in the sample are $26 \%, 12 \%$, and $42 \%$, respectively, which further confirms the composition of phase-pure $\mathrm{Ag}_{10} \mathrm{Si}_{4} \mathrm{O}_{13}$. Fig. $1 \mathrm{~d}$ shows the diffuse reflectance spectrum of $\mathrm{Ag}_{10} \mathrm{Si}_{4} \mathrm{O}_{13}$ collected by ultraviolet-visible (UV-Vis) spectroscopy. The absorption edge is located at about $700 \mathrm{~nm}$. The band gap $\left(E_{\mathrm{g}}\right)$ of $\mathrm{Ag}_{10} \mathrm{Si}_{4} \mathrm{O}_{13}$ was then estimated to be 1.72 $\mathrm{eV}$ according to the Tauc formula, ${ }^{30}$ as is shown in the upper right inset of Fig. 1d. It indicates that $\mathrm{Ag}_{10} \mathrm{Si}_{4} \mathrm{O}_{13}$ can absorb almost all the visible-light spectrum.

The narrow band gap of the as-prepared $\mathrm{Ag}_{10} \mathrm{Si}_{4} \mathrm{O}_{13}$ sample is believed to have arisen from the hybridization of different orbitals in this Ag-incorporated p-block compound. Thus, density functional theory (DFT) calculations were carried out in order to reveal the electronic structure of $\mathrm{Ag}_{10} \mathrm{Si}_{4} \mathrm{O}_{13}$. The calculated band structure is shown in Fig. 2a. The band gap is calculated as $1.71 \mathrm{eV}$, which agrees well with our experimental results based on the photo-absorption edge. The high symmetry points of the $C B$ and VB are located at the $\Gamma$ and $Z$ points, respectively, giving $\mathrm{Ag}_{10} \mathrm{Si}_{4} \mathrm{O}_{13}$ the features of a typical indirect band-gap semiconductor. It is well known that the excited electrons in an indirect-band-gap semiconductor have a longer lifetime. The separation and migration of photoinduced charge carriers are thus expected to be more efficient. Moreover, a typical signature band structure of the $p$-block configuration is revealed by our DFT results, in which the CB is highly dispersive whereas the $\mathrm{VB}$ shows much less dispersion in $\mathrm{Ag}_{10} \mathrm{Si}_{4} \mathrm{O}_{13}$. As shown in Fig. $2 \mathrm{~b}$, the $\mathrm{CB}$ of $\mathrm{Ag}_{10} \mathrm{Si}_{4} \mathrm{O}_{13}$ mainly consists of $\mathrm{Ag} 5 \mathrm{~s}$ and $5 p$ orbitals. The large amount of hybridization between $\mathrm{Ag} s$ and $\mathrm{Ag} p$ occurs due to short $\mathrm{Ag}-\mathrm{Ag}$ bonds. This indicates that the $C B$ is constructed without the "contamination" of less dispersive $d$ states. As a result, the photo-excited electrons have a small effective mass, which enables photo-excited electrons to easily move to surface active sites due to their high mobility. In contrast, the VB of $\mathrm{Ag}_{10} \mathrm{Si}_{4} \mathrm{O}_{13}$ is mainly contributed by $\mathrm{Ag} 4 \mathrm{~d}$ orbitals. This leads to a flatter band (as compared to the $\mathrm{CB}$ ) and thus generates "heavy" holes in the photo-excitation process. This electronic configuration suggests high quantum conversion efficiency for $\mathrm{Ag}_{10} \mathrm{Si}_{4} \mathrm{O}_{13}$ under visible light. It is well known that the energy positions of the $C B$ and $V B$ are the primary factors that determine whether the semiconductor can be used in photocatalytic reduction or oxidation. We therefore carried out Mott-Schottky measurements of $\mathrm{Ag}_{10} \mathrm{Si}_{4} \mathrm{O}_{13}$, as shown in Fig. 2c. The relative position of the $C B$ edge can be calculated from the empirical equation ${ }^{31}: E_{\mathrm{c}}=\chi-0.5 E_{\mathrm{g}}+E_{0}$, where $E_{0}$ is a scale factor relating the reference electrode redox level to the absolute vacuum scale $\left(E_{0}=-4.5 \mathrm{eV}\right.$ for normal hydrogen electrode (NHE)), $E_{\mathrm{g}}$ is the band gap, and $\chi$ is the absolute electronegativity of the semiconductor. The calculated $E_{\mathrm{c}}$ from this equation is empirical and theoretical. Therefore, electrochemical flat-band potential measurements were adopted. The flat-band potential values are obtained by the Mott-Schottky equation ${ }^{32,33}$ :

$$
\frac{1}{C^{2}}=\frac{2}{\varepsilon \varepsilon_{0} N_{D}}\left(E-E_{f b}-\frac{k_{B} T}{q}\right)
$$

where $C$ is the space charge capacitance, $N_{D}$ is the donor density, $\varepsilon$ and $\varepsilon_{0}$ are the dielectric constants of free space and the film electrode, respectively, $E$ is the applied potential, $E_{\mathrm{fb}}$ is the flat-band potential, $k_{\mathrm{B}}$ is Boltzmann's constant, $T$ is the temperature, and $q$ is the electronic charge. The $E_{\mathrm{fb}}$ value can be determined from the extrapolation to $1 / C^{2}=0$, as shown in Fig. 2c. The flat potential is calculated to be $0.523 \mathrm{~V}$ versus saturated calomel electrode (SCE), which is equivalent to 0.729 $\mathrm{V}$ ( $\mathrm{NHE}$ vs. $\mathrm{Ag} / \mathrm{AgCl}=0.206 \mathrm{~V}$ ). It is well accepted that the $\mathrm{CB}$ of $n$-type semiconductors is about $-0.1 \mathrm{~V}$ higher than the flat potentials, depending on the electron effective mass and carrier concentration. With an applied voltage difference of $0.05 \mathrm{eV}$ between the conduction band and the flat potential, the bottom of the CB is derived as $0.679 \mathrm{eV}$. The inset in Fig. $2 \mathrm{c}$ shows a schematic diagram of the redox potential of $\mathrm{Ag}_{10} \mathrm{Si}_{4} \mathrm{O}_{13}$, corresponding to the Mott-Schottky fitting result. The $C B$ and $V B$ edges (inset Fig. 2c) of $\mathrm{Ag}_{10} \mathrm{Si}_{4} \mathrm{O}_{13}$ are $+0.679 \mathrm{eV}$ and $+2.4 \mathrm{eV}$ vs. NHE, respectively. The lower potential of the VB with respect to the $\mathrm{O}_{2} / \mathrm{H}_{2} \mathrm{O}$ redox potential indicates that 
$\mathrm{Ag}_{10} \mathrm{Si}_{4} \mathrm{O}_{13}$ possesses strong photo-oxidative capabilities and can be used as an oxidative photocatalyst.

In view of the possible strong photo-oxidative capability, the photocatalytic activity of $\mathrm{Ag}_{10} \mathrm{Si}_{4} \mathrm{O}_{13}$ was evaluated by the photodegradation of organic compounds, including Rhodamine B (RhB), Methyl orange (MO), methylene blue $(\mathrm{MB})$, and phenol, under visible light irradiation. The results are shown in Fig. 3 and in (Fig. S2a and S2b+). All the photocatalytic degradation measurements were carried out after the dark reaction, in which the equilibrium adsorption states were reached.

The $\mathrm{Ag}_{10} \mathrm{Si}_{4} \mathrm{O}_{13}$ sample exhibits excellent visible-light photocatalytic degradation activity, which is better than that of $\mathrm{N}$ doped $\mathrm{TiO}_{2}$ and the other AgO-based reference samples. For example, under visible-light irradiation, the absorption peak of $\mathrm{MB}$ at $664 \mathrm{~nm}$ decreased rapidly with increasing irradiation time and eventually disappeared after $40 \mathrm{~min}$, suggesting excellent photocatalytic performance of the $\mathrm{Ag}_{10} \mathrm{Si}_{4} \mathrm{O}_{13}$ (Fig. 3a). This demonstrates that the $\mathrm{MB}$ can be completely degraded by $\mathrm{Ag}_{10} \mathrm{Si}_{4} \mathrm{O}_{13}$ under visible light. The inset in Fig. 3a shows the visible changes in the color concentration of the MB solution during the photo-oxidation process. The excellent photocatalytic degradation activities of $\mathrm{Ag}_{10} \mathrm{Si}_{4} \mathrm{O}_{13}$ were also demonstrated with the other dyes, which are shown in (Fig. S2a, S2b+). By monitoring the signature absorption peaks of RhB, MB, and $\mathrm{MO}$ at $556 \mathrm{~nm}, 664 \mathrm{~nm}$, and $470 \mathrm{~nm}$, respectively, plots of the visible-light degradation ratio versus reaction time were obtained and are shown in Fig. $3 \mathrm{~b}$. We note that the complete degradation of $\mathrm{MB}$ and $\mathrm{RhB}$, and the $80 \%$ degradation of $\mathrm{MO}$ can be achieved after $30 \mathrm{~min}$, $40 \mathrm{~min}$, and $40 \mathrm{~min}$, respectively. The photocatalytic degradation reaction of the samples followed the pseudo-firstorder linear relationship with reaction rate constants $(k)$ as shown in the inset of Fig. $3 \mathrm{~b}$. The photocatalytic stability of $\mathrm{Ag}_{10} \mathrm{Si}_{4} \mathrm{O}_{13}$ in photodegradation was also studied by a photocatalytic cycling test, as shown in (Fig. $\left.\mathrm{S}^{+}\right)^{\text {). }} \mathrm{Ag}_{10} \mathrm{Si}_{4} \mathrm{O}_{13}$ shows stable photocatalytic performance for eight photocatalytic degradation cycles. The decreased photocatalytic activity in the first several rounds is due to initial instability of $\mathrm{Ag}_{10} \mathrm{Si}_{4} \mathrm{O}_{13}$, which is general for the other Ag-based photocatalysts. ${ }^{34,35}$ It is believed that a small amount of $\mathrm{Ag}$ nanoparticles form on the surface of $\mathrm{Ag}_{10} \mathrm{Si}_{4} \mathrm{O}_{13}$ at the very beginning photocatalytic cycles. These Ag nanoparticles then function as electron trapping centres to suppress further photocorrosion of the samples, which is evident by stable photocatalytic performance after third run. It should be noted that our $\mathrm{Ag}_{10} \mathrm{Si}_{4} \mathrm{O}_{13}$ sample shows much higher photo-oxidation activity than the $\mathrm{N}$ doped $\mathrm{TiO}_{2}$ reference sample under visiblelight, as shown in Fig. 3c, which verifies its excellent visiblelight photocatalytic activity towards degradation of organics. We also carried out photocatalytic degradation of colorless phenol over our $\mathrm{Ag}_{10} \mathrm{Si}_{4} \mathrm{O}_{13}$ sample under visible light irradiation. As shown in Fig. 3d and Fig. S4at, it is found that the phenol can be completely degraded in $80 \mathrm{~min}$. The inset in Fig. $3 d$ shows the plots of the rate constants $(k)$ versus reaction time. The above results confirm that the photocatalytic dye degradation activity of $\mathrm{Ag}_{10} \mathrm{Si}_{4} \mathrm{O}_{13}$ cannot be attributed to the dye-sensitization effect because the colorless phenol only absorbs light with wavelengths of $260-280 \mathrm{~nm}$. The $\mathrm{k}$ of $\mathrm{MB}$, $\mathrm{MO}, \mathrm{RhB}$ and phenol were $6,2.68,5.7,2.7 \mathrm{~s}^{-1}$ respectively as shown in (Table $\mathrm{S} 1+$ ). and the apparent quantum efficiency were $0.78,0.83,1.23,5.9$ respectively. ${ }^{36}$

The mechanism behind the excellent visible-light photocatalytic activity of our $\mathrm{Ag}_{10} \mathrm{Si}_{4} \mathrm{O}_{13}$ sample was investigated. It is well known that the photocatalytic activity is dominated by several chemical dynamic processes in photocatalysis, including charge excitation, charge separation, and charge transfer. In our photocatalytic degradation measurements, $\mathrm{Ag}_{10} \mathrm{Si}_{4} \mathrm{O}_{13}$ shows superior photocatalytic activity relative to $\mathrm{N}$ doped $\mathrm{TiO}_{2}$ and the other $\mathrm{Ag}$-based $p$ block photocatalysts (see Fig. $\mathrm{S} 4 \mathrm{~b}+$ ). This indicates that one or several key steps involved in the photocatalytic dynamics under visible light would be promoted by the electronic structure of $\mathrm{Ag}_{10} \mathrm{Si}_{4} \mathrm{O}_{13}$. We carried out photocurrent response measurements of $\mathrm{Ag}_{10} \mathrm{Si}_{4} \mathrm{O}_{13}$ under visible light irradiation, as shown in (Fig. S5at). It can be seen that the photocurrent generated in $\mathrm{Ag}_{10} \mathrm{Si}_{4} \mathrm{O}_{13}$ under visible light is $1.4 \times 10^{-1} \mathrm{~mA} / \mathrm{cm}^{2}$, which is higher than that $\left(1 \times 10^{-1} \mathrm{~mA} / \mathrm{cm}^{2}\right)$ of a typical visiblelight-driven $\mathrm{AgO}$-based photocatalyst $\mathrm{Ag}_{3} \mathrm{PO}_{4} \cdot{ }^{37}$ The ON-OFF cycles measurement of photocurrent demonstrates that $\mathrm{Ag}_{10} \mathrm{Si}_{4} \mathrm{O}_{13}$ possesses high quantum conversion efficiency, and there is a low recombination rate of photo-induced charge carriers under visible-light illumination. It should note that gradually decrease of photocurrent at first three cycles is due to photocorrosion of sample as a result of formation of $\mathrm{Ag}$ nanoparticles. We went on to collect surface photovoltage spectra (Fig. $\mathrm{S} \mathrm{b}^{+}$), which confirms the high separation rate of photo-induced charge carriers in $\mathrm{Ag}_{10} \mathrm{Si}_{4} \mathrm{O}_{13}$, especially in the spectral range from 300 to $600 \mathrm{~nm}$. The efficient separation of photo-induced charges is most likely the key factor contributing to the excellent photocatalytic activity of $\mathrm{Ag}_{10} \mathrm{Si}_{4} \mathrm{O}_{13}$, as compared to the other $p$-block photocatalysts.

In fact, the separation of electron-hole pairs in $\mathrm{Ag}_{10} \mathrm{Si}_{4} \mathrm{O}_{13}$ would not be expected to be so effective if one only considered its electronic structure. The reasons for the greater efficiency are as follows: Firstly, the charge recombination process also takes advantage of the dispersive band structure in $\mathrm{Ag}_{10} \mathrm{Si}_{4} \mathrm{O}_{13}$. The chances for separation and recombination would be traded off in the photocatalytic process. Secondly, our DFT results reveal that photo-induced holes in $\mathrm{Ag}_{10} \mathrm{Si}_{4} \mathrm{O}_{13}$ possess a large effective mass due to the relatively flat VB. This would be expected to limit the movement of photo-induced holes to surface active sites of $\mathrm{Ag}_{10} \mathrm{Si}_{4} \mathrm{O}_{13}$, and thereby, limit the photo-oxidative activity of $\mathrm{Ag}_{10} \mathrm{Si}_{4} \mathrm{O}_{13}$. Nevertheless, this is obviously contradictory to our results on the photocatalytic degradation of dyes and phenol in Fig. 3. Therefore, it is suspected that the effective separation of photo-induced charge carriers in $\mathrm{Ag}_{10} \mathrm{Si}_{4} \mathrm{O}_{13}$ is caused by another mechanism in addition to the $p$-block electronic configuration.

In $\mathrm{Ag}_{x} \mathrm{Si}_{y} \mathrm{O}_{z}$ compounds, an internal electric field may exist due to the distorted $\mathrm{SiO}_{4}$ tetrahedral chains that are formed in the crystal structure. This internal electric field can overcome charge recombination and promote spatial separation of electrons and holes. Interestingly, $\mathrm{Ag}_{10} \mathrm{Si}_{4} \mathrm{O}_{13}$ has the longest 
distorted $\mathrm{SiO}_{4}$ chains in the $\mathrm{Ag}_{x} \mathrm{Si}_{y} \mathrm{O}_{z}$ family. They most likely induce an internal field due to spontaneous polarization. In order to verify this, a ferroelectric polarization measurement was conducted. As shown in Fig. 4a, we observed the ferroelectric polarization-electric field $(P-E)$ hysteresis loops of $\mathrm{Ag}_{10} \mathrm{Si}_{4} \mathrm{O}_{13}$, which were obtained through a pulsed positive-upnegative-down (PUND) polarization measurement. A typical unsaturated ferroelectric hysteresis loop with a remanent polarization $\left(P_{\mathrm{r}}\right)$ of $0.05 \mu \mathrm{C} / \mathrm{cm}^{2}$ was obtained in electric field of $100 \mathrm{~V} / \mathrm{cm}$, as shown in Fig. 4a. This result verifies the existence of an internal electric field in $\mathrm{Ag}_{10} \mathrm{Si}_{4} \mathrm{O}_{13}$ due to an intrinsic electric polarization. Corresponding to the DFT-simulated three-dimensional (3D) charge density distribution (Fig. 4b), the spontaneous electric polarization in $\mathrm{Ag}_{10} \mathrm{Si}_{4} \mathrm{O}_{13}$ is attributed to misaligned positive and negative charge centers in the $\mathrm{Ag}_{10} \mathrm{Si}_{4} \mathrm{O}_{13}$ unit cells, in which $\mathrm{O}$ is the charge acceptor and $\mathrm{Si}$ is the main charge donor, with little charge decrease for $\mathrm{Ag}$ in the crystal. This result suggests that the spontaneous electric polarization in $\mathrm{Ag}_{10} \mathrm{Si}_{4} \mathrm{O}_{13}$ is attributable to misaligned positive and negative charge centers, which are mainly induced by the asymmetrical $\mathrm{Si}-\mathrm{O}$ tetrahedral chains in $\mathrm{Ag}_{10} \mathrm{Si}_{4} \mathrm{O}_{13}$ unit cells. Given this structure, the calculated spontaneous polarization is about $64.78 \mu \mathrm{C} / \mathrm{cm}^{2}$, and the polarization direction is indicated in Fig. 4(c). We also find that the 01-O1 bonds in the chains are twisted with angles of 143을 and 166.4ㅇ (Fig. S6+), accompanied by a coherent displacement of the Ag ions, as well as a distortion of the 03 . The $\mathrm{SiO}_{4}$ tetrahedra show a spiral distortion with respect to each other on the $\mathrm{SiO}_{4}$ chains. The spontaneous polarization along the $c$ direction is induced by the relative displacement of these anionic $\mathrm{SiO}_{4}$ tetrahedral units and cationic $\mathrm{Ag}-\mathrm{O}$ layers. Concurrently, the $\mathrm{Ag}$ ions are slightly shifted to a direction normal to the O3, thereby also creating electronic polarization along the $a$ direction. The internal electric field is believed to be the main driving force for charge separation in $\mathrm{Ag}_{10} \mathrm{Si}_{4} \mathrm{O}_{13}$. Our investigation has demonstrated that the excellent visible-light photocatalytic activity of $\mathrm{Ag}_{10} \mathrm{Si}_{4} \mathrm{O}_{13}$ is attributable to its $p$-block electronic structure as well as structural distortion, which provides a new strategy to design and develop visible-light-driven photocatalysts to eliminate pollution.

\section{Conclusions}

The visible-light-driven photocatalyst $\mathrm{Ag}_{10} \mathrm{Si}_{4} \mathrm{O}_{13}$ was synthesized by the ion-exchange method. It was found that $\mathrm{Ag}_{10} \mathrm{Si}_{4} \mathrm{O}_{13}$ possesses excellent photocatalytic performance towards degradation of dyes and phenol over the entire visible light spectrum. The photocatalytic activity of $\mathrm{Ag}_{10} \mathrm{Si}_{4} \mathrm{O}_{13}$ is attributed to high quantum conversion efficiency because of its narrow band gap, dispersive band structure, and internal electric field. This unique electronic structure and internal electric field originate from the $p$-block electronic configuration and distorted $\mathrm{SiO}_{4}$ chains in $\mathrm{Ag}_{10} \mathrm{Si}_{4} \mathrm{O}_{13}$.

\section{Acknowledgements}

This work is supported by the Australian Research Council (ARC) through a Discovery Project (DP 140102581), the National Natural Science Foundation of China (Grant No. 51072012, No. 51272015), the Fundamental Research Funds for the Central Universities (Grand No.: YWF-16-JCTD-B-03), and the Beijing Key Discipline Foundation of Condensed Matter Physics). The authors acknowledge the service supported by Electronic Microscopy Centre at the University of Wollongong. The authors thank Dr. T. Silver for her valuable comments on this work.

\section{References}

1 A. Fujishima and K. Honda, Nature, 1972, 238, 37-38.

2 V. Vaiano, O. Sacco, D. Sannino and P. Ciambelli, Chem. Eng. J., 2015, 261, 3-8.

3 O. Sacco, V. Vaiano, C. Han, D. Sannino and D. D. Dionysiou, Appl. Catal. B, 2015, 164, 462-472.

4 M. Takeuchi, H. Yamashita, M. Matsuoka, M. Anpo, T. Hirao, N. Itoh and N. Iwamoto, Catal. Lett., 2000, 66, 185-187.

5 S. Klosek and D. Raftery, J. Phys. Chem. B, 2001, 105, 28152819.

6 M. Khan, S. R. Gul, J. Li, W. Cao and A. G. Mamalis, Mater. Res. Express, 2015, 2, 066201.

7 Q. Wang, M. Chen, N. Zhu, X. Shi, H. Jin, Y. Zhang and Y. Cong, J. Colloid Interface Sci., 2015, 448, 407-416.

8 K. M. Cho, K. H. Kim, H. O. Choi and H.-T. Jung, Green Chem., 2015, 17, 3972-3978.

9 M. Aslam, I. M. I. Ismail, S. Chandrasekaran and A. Hameed, J. Hazard. Mater., 2014, 276, 120-128.

10 D. Lang, Q. Xiang, G. Qiu, X. Feng and F. Liu, Dalton Trans., 2014, 43, 7245-7253.

11 J. Shang, W. Hao, X. Lv, T. Wang, X. Wang, Y. Du, S. Dou, T. Xie, D. Wang and J. Wang, ACS Catal., 2014, 4, 954-961.

12 C. Janáky, K. Rajeshwar, N. R. de Tacconi, W. Chanmanee and M. N. Huda, Catal. Today, 2013, 199, 53-64.

13 F. Meng, J. Li, Z. Hong, M. Zhi, A. Sakla, C. Xiang and N. Wu, Catal. Today, 2013, 199, 48-52.

14 Z. Shu, X. Jiao and D. Chen, CrystEngComm, 2013, 15, 42884294.

15 H. Yan, X. Wang, M. Yao and X. Yao, Prog. Nat. Sci., 2013, 23, 402-407.

16 C. Xu, Y. Liu, B. Huang, H. Li, X. Qin, X. Zhang and Y. Dai, Appl. Surf. Sci., 2011, 257, 8732-8736.

17 S. Ouyang, N. Kikugawa, Z. Zou and J. Ye, Appl. Catal. A, 2009, 366, 309-314.

18 Y. Maruyama, H. Irie and K. Hashimoto, J. Phys. Chem. B, 2006, 110, 23274-23278.

19 T.-G. Kim, D.-H. Yeon, T. Kim, J. Lee and S.-J. Im, Appl. Phys. Lett., 2013, 103, 043904.

20 X. Zhu, Z. Wang, B. Huang, W. Wei, Y. Dai, X. Zhang and X. Qin, APL Mater., 2015, 3, 104413.

21 J. Zhao, Z. Ji, C. Xu, X. Shen, L. Ma and X. Liu, Cryst. Res. Technol., 2014, 49, 975-981.

22 J. Tang, D. Li, Z. Feng, Z. Tan and B. Ou, RSC Adv., 2014, 4, 2151-2154.

23 K. Yu, S. Yang, C. Liu, H. Chen, H. Li, C. Sun and S. A. Boyd, Environ. Sci. Technol., 2012, 46, 7318-7326.

24 Z. Lou, B. Huang, Z. Wang, X. Ma, R. Zhang, X. Zhang, X. Qin, Y. Dai and M.-H. Whangbo, Chem. Mater., 2014, 26, 38733875.

25 H. Feng, Z. Xu, L. Wang, Y. Yu, D. Mitchell, D. Cui, X. Xu, J. Shi, T. Sannomiya, Y. Du, W. Hao and S. X. Dou, ACS Appl. Mater. Interfaces, 2015, 7, 27592-27596. 
26 L. Wang, J. Shang, W. Hao, S. Jiang, S. Huang, T. Wang, Z. Sun, Y. Du, S. Dou, T. Xie, D. Wang and J. Wang, Sci. Rep., 2014, 4, 7384.

27 H. Taniguchi, A. Kuwabara, J. Kim, Y. Kim, H. Moriwake, S. Kim, T. Hoshiyama, T. Koyama, S. Mori, M. Takata, H. Hosono, Y. Inaguma and M. Itoh, Angew. Chem. Int. Ed., 2013, 52, 8088-8092.

28 D. Seol, H. Taniguchi, J.-Y. Hwang, M. Itoh, H. Shin, S. W. Kim and Y. Kim, Nanoscale, 2015, 7, 11561-11565.

29 T. H. Akira SAHASHI, Hiroaki TAKEDA and Takaaki TSURUMI, J. Ceram. Soc. Jpn., 2014, 122, 389-392.

30 J. Tauc, R. Grigorovici and A. Vancu, Phys. Status Solidi B 1966, 15, 627-637.

31 M. A. Butler and D. S. Ginley, J. Electrochem. Soc., 1978, 125, 228-232.

32 K. Gelderman, L. Lee and S. W. Donne, J. Chem. Educ., 2007 84, 685.

33 F. Cardon and W. P. Gomes, J. Phys. D: Appl. Phys., 1978, 11, L63.

34 D. Xu, B. Cheng, J. Zhang, W. Wang, J. Yu, W. Ho, J. Mater. Chem A, 2015, 3, 20153-20166.

35 Z. Yi, J. H. Ye, N. Kikugawa, T. Kako, S. Ouyang, H. StuartWilliams, H. Yang, J. Cao, W. Luo, Z. Li, Y. Liu and R. L. Withers. Nat. Mater., 2010, 9, 559-564.

36 J. M. Buriak, P. V. Kamat and K. S. Schanze, ACS Appl. Mater. Interfaces, 2014, 6, 11815-11816.

37 C. Cui, Y. Wang, D. Liang, W. Cui, H. Hu, B. Lu, S. Xu, X. Li, C. Wang and Y. Yang, Applied Catalysis B: Environmental, 2014, 158-159, 150-160. 


\section{Figures, Scheme, Charts}
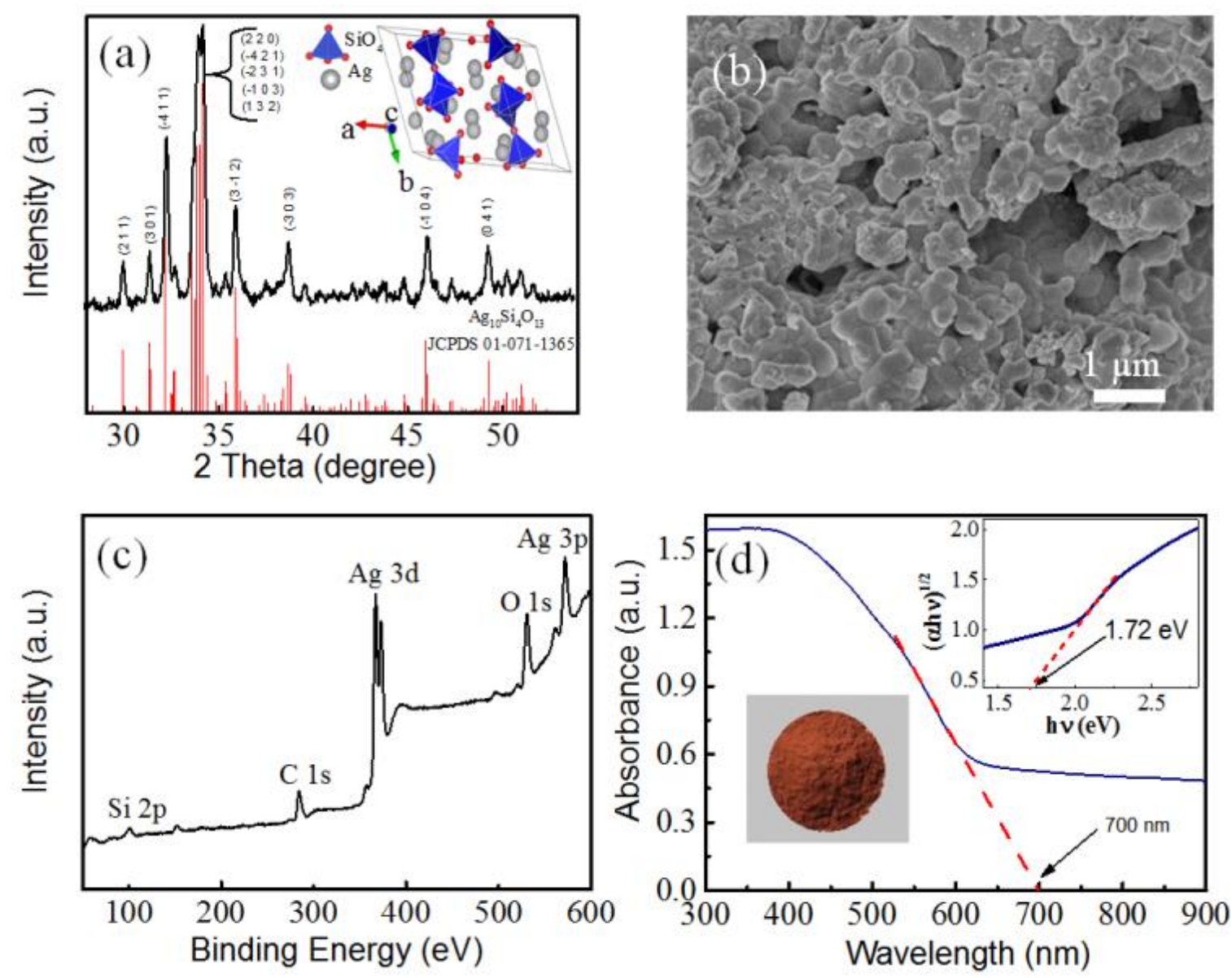

Figure 1 (a) XRD pattern of as-prepared $\mathrm{Ag}_{10} \mathrm{Si}_{4} \mathrm{O}_{13}$. The inset is the crystal structure of $\mathrm{Ag}_{10} \mathrm{Si}_{4} \mathrm{O}_{13}$. (b) SEM image of as-prepared $\mathrm{Ag}_{10} \mathrm{Si}_{4} \mathrm{O}_{13}$ sample. (c) XPS result of as-prepared $\mathrm{Ag}_{10} \mathrm{Si}_{4} \mathrm{O}_{13}$. (d) UV-vis diffuse reflectance spectra of $\mathrm{Ag}_{10} \mathrm{Si}_{4} \mathrm{O}_{13}$. Inset at right top of (d) is the derivation of the band gap value of as-prepared $\mathrm{Ag}_{10} \mathrm{Si}_{4} \mathrm{O}_{13}$ which is derived from diffuse reflectance spectrum. Inset at left bottom of (d) is photograph of the as-prepared photocatalyst. 

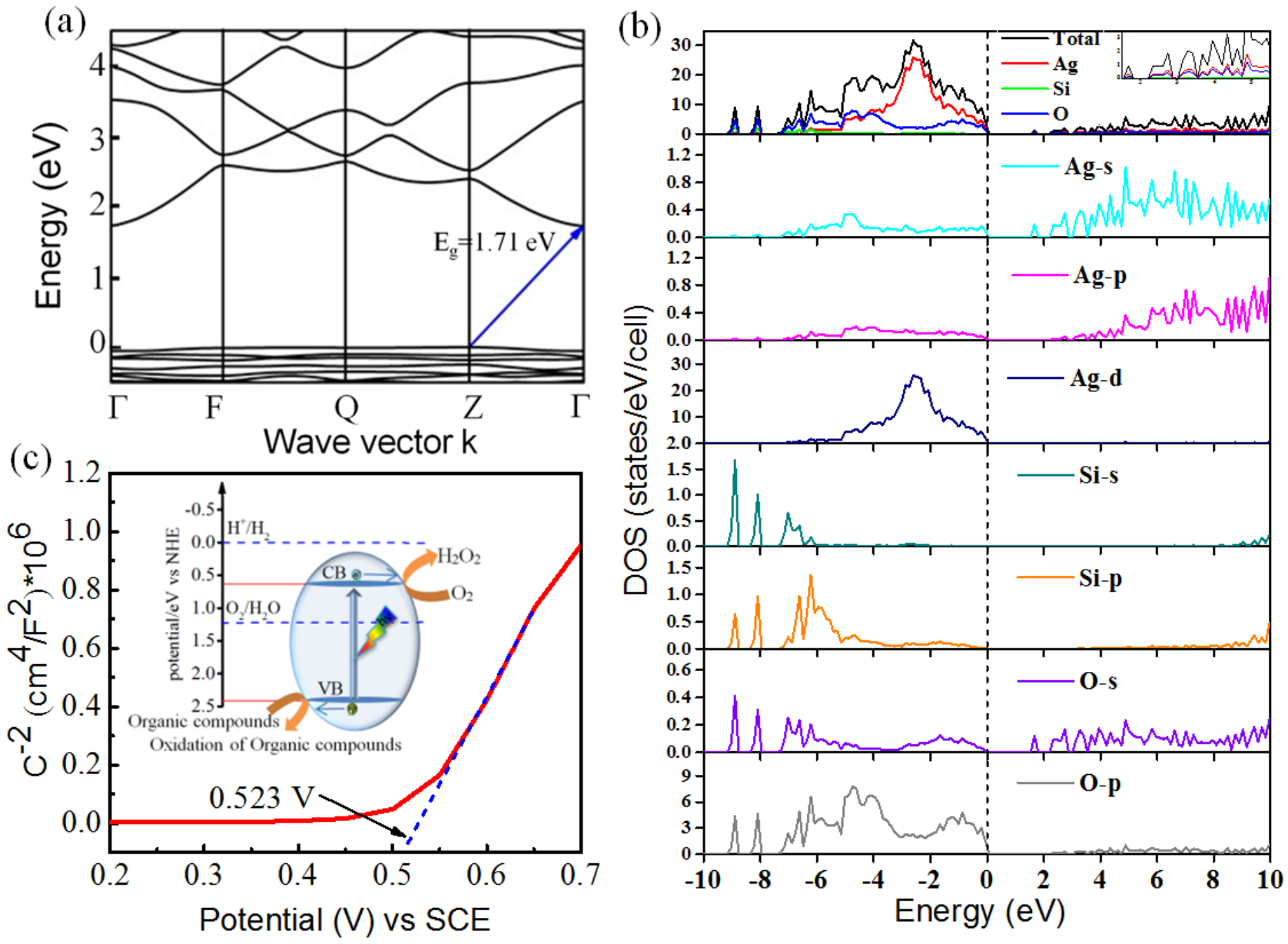

Figure 2 (a) DFT calculated electronic structure of $\mathrm{Ag}_{10} \mathrm{Si}_{4} \mathrm{O}_{13}$, in which a dispersive $\mathrm{CB}$ and flat VB can be observed. (b) Partial density of states calculated by DFT. (c) Mott- Schottky plot of pure $\mathrm{Ag}_{10} \mathrm{Si}_{4} \mathrm{O}_{13}$. The flat band potential is determined to be about $0.523 \mathrm{~V}$. The inset is a schematic diagram of the redox potential of $\mathrm{Ag}_{10} \mathrm{Si}_{4} \mathrm{O}_{13}$, corresponding to the Mott-Schottky fitting results schematic of band-edge potentials of $\mathrm{Ag}_{10} \mathrm{Si}_{4} \mathrm{O}_{13}$. 
(a)

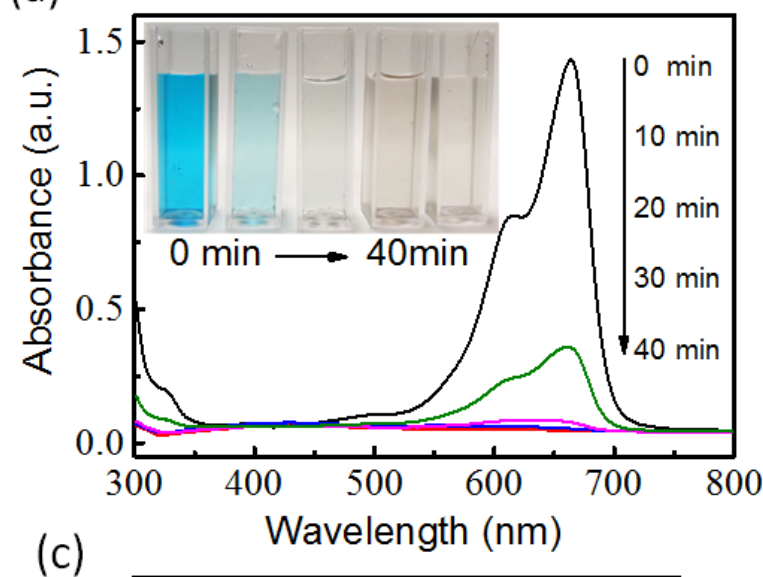

(c)

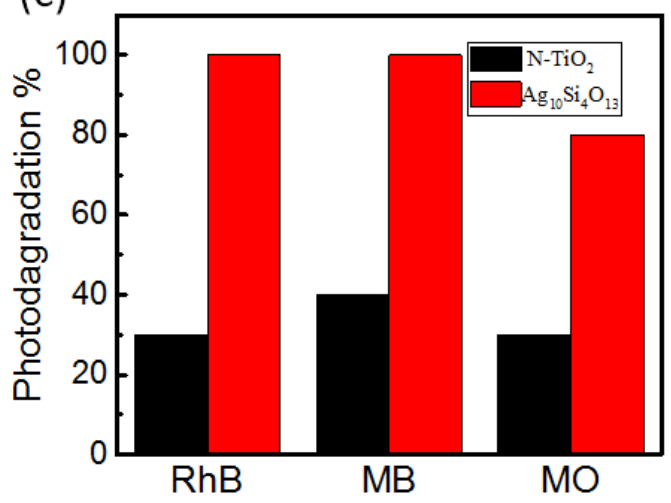

(b)
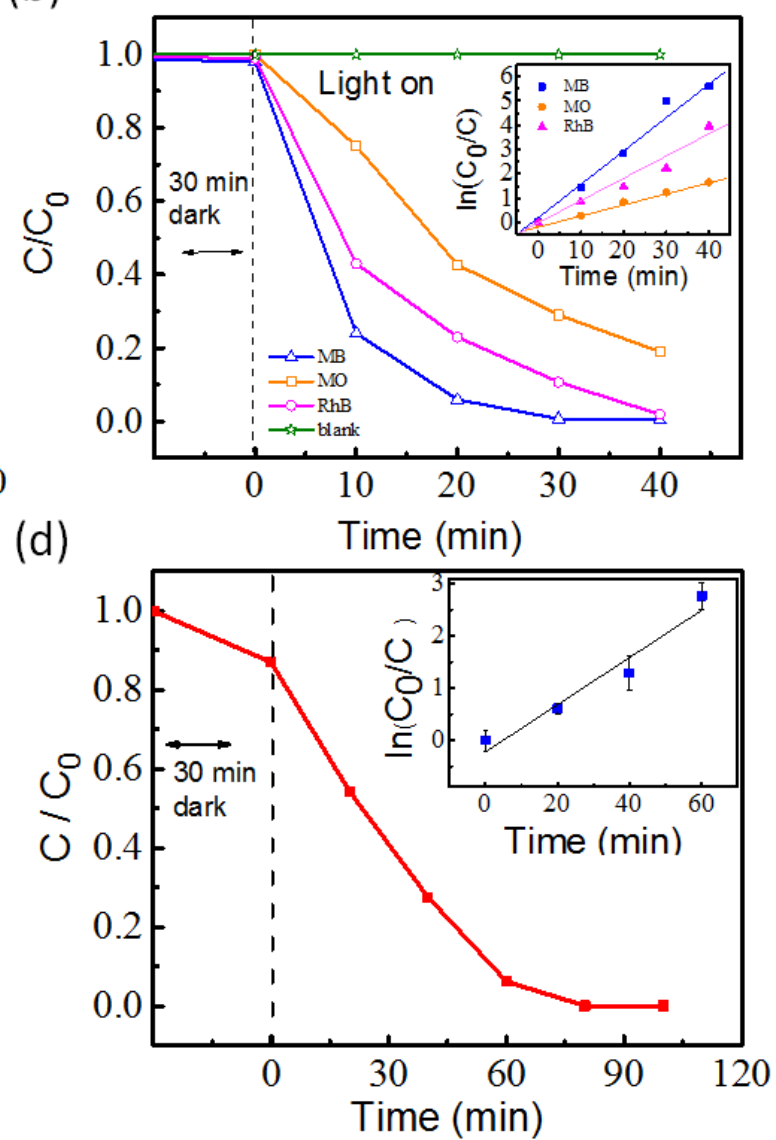

Figure 3 (a) UV-Visible absorbance spectra for photodegradation of $\mathrm{MB}$ dye over $\mathrm{Ag}_{10} \mathrm{Si}_{4} \mathrm{O}_{13}$ under visible light, recorded after different degradation times. The inset shows the color changes of the MB solutions corresponding to the five degradation times from 0 min to 40 min. (b) Photodegradation rate of organic dyes over $\mathrm{Ag}_{10} \mathrm{Si}_{4} \mathrm{O}_{13}$ under visible light. The inset show kinetic study of photocatalytic degradation process of organic dyes under visible light over $\mathrm{Ag}_{10} \mathrm{Si}_{4} \mathrm{O}_{13}$. (c) Comparison of photodegradation percentages of $\mathrm{Ag}_{10} \mathrm{Si}_{4} \mathrm{O}_{13}$ and $\mathrm{N}$ doped $\mathrm{TiO}_{2}\left(\mathrm{~N}-\mathrm{TiO}_{2}\right)$ under visible light for different organic dyes. (d) Photodegradation rate of phenol under visible light over $\mathrm{Ag}_{10} \mathrm{Si}_{4} \mathrm{O}_{13}$. The inset show kinetic study of photocatalytic degradation process of phenol under visible light over $\mathrm{Ag}_{10} \mathrm{Si}_{4} \mathrm{O}_{13}$. 
(a)

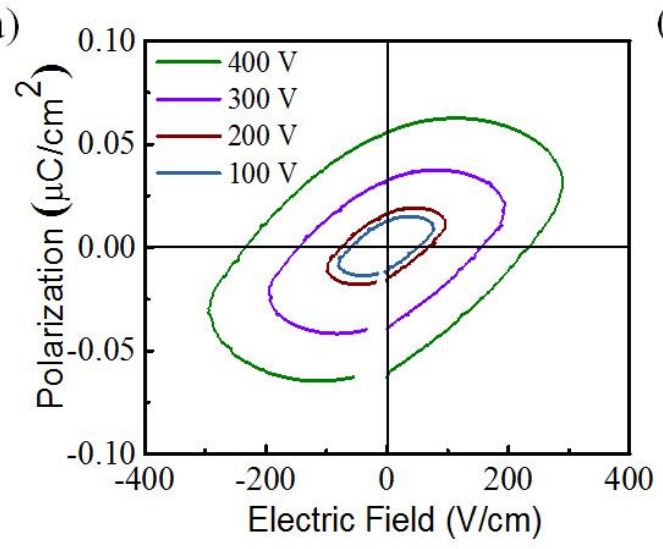

(b)

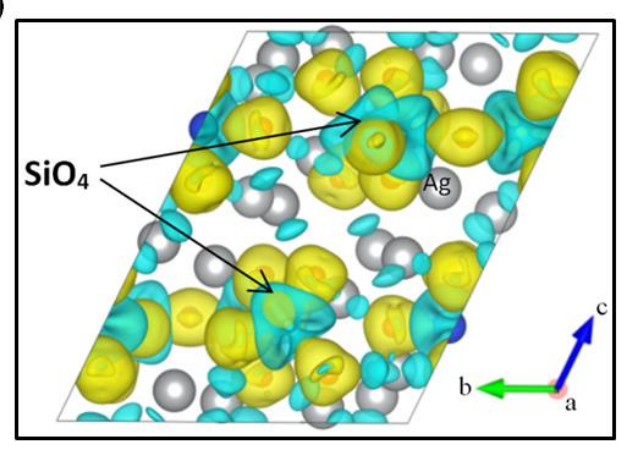

(c)

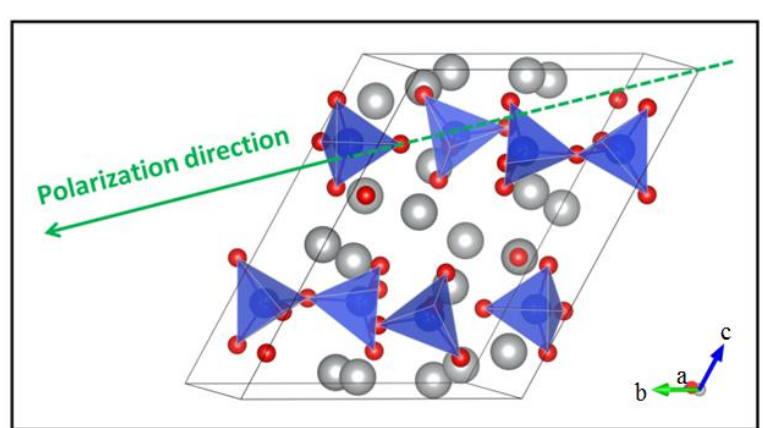

Figure 4 (a) P-E hysteresis loop of $\mathrm{Ag}_{10} \mathrm{Si}_{4} \mathrm{O}_{13}$ at different applied voltage and frequency $1 \mathrm{kHz}$. (b) Charge density maps, the isosurfaces are $0.01 \mathrm{e} / \AA^{3}$ of $\mathrm{Ag}_{10} \mathrm{Si}_{4} \mathrm{O}_{13}$. (c) Crystal structure of $\mathrm{Ag}_{10} \mathrm{Si}_{4} \mathrm{O}_{13}$ to show polarization direction. 